\title{
Trabeculectomy around the globe
}

JP Diamond

\section{Eye (2005) 19, 241-242. doi:10.1038/sj.eye.6701601}

Thirty seven years after Cairns described the procedure, trabeculectomy remains the operation of choice for patients with uncontrolled glaucoma. Trabeculectomy has survived predictions forecasting its imminent demise following arrival of topical prostaglandins and nonpenetrating surgery. Indeed, the recent demonstration that effective pressure reduction protects against progressive field loss may promote an increased use of trabeculectomy surgery.

The publication of the early manifest glaucoma trial has shown that glaucoma patients with consistently low intraocular pressures have a significant reduction in the progression of their visual field loss. ${ }^{1}$

Trabeculectomy remains perhaps the most effective method for reducing the intraocular pressure to those safer levels between 10 and $15 \mathrm{mmHg}$.

Several authors including Migdal and Jay ${ }^{2,3}$ have investigated the proposal that early tabeculectomy surgery represents the optimal method for preventing glaucoma damage. Their results have supported the hypothesis that primary surgery may have a role to play in management of some patients. Most surgeons, however, employ trabeculectomy surgery only when conventional medical management has failed, their reservation about primary surgery reflecting anxiety about the associated risks (eg cataract, hypotony) allied to concern about allocation of resource.

Trabeculectomy surgery has not stood still since its inception. Improved understanding of both the causes of surgical failure and the aetiology of many surgical complications has led to a number of advances including releasable flap sutures ${ }^{4}$ and the employment of antimetabolites to prevent closure of the drainage fistula. ${ }^{5}$ Modern trabeculectomy surgery can be considered a safer and more predictable procedure than its earlier incarnations.
Indeed, it is the recognition that improved understanding of the natural history of trabeculectomy surgery facilitates the management of a given patient or population of patients with glaucoma. The awareness that black patients (who are often predisposed to severe glaucoma at a young age) are prone to a vigorous healing response resulting in closure of their drainage fistula, has led to the widespread employment of antimetabolites in these patient groups.

While several large epidemiological studies have generated data pertaining to the prevalence and severity of glaucoma in black patients in the United States ${ }^{6}$ and the Caribbean, ${ }^{7}$ there have been fewer studies investigating the populations of east Asia. ${ }^{8}$ Moreover, there is a need for prospective studies to evaluate the natural history of open-angle glaucoma in these same populations.

The paper from Husain in this journal represents a valuable review of those factors, which influence the outcome of trabeculectomy surgery in the people of east Asia. This population is already large and growing rapidly. At present, there is little evidence to quantify the outcome of surgery in this population, nor indeed to guide the clinician on selection of the most suitable surgical technique to employ for this patient group.

East Asia has huge variations in per-capita income allied to availability of modern medical care. Japan, Singapore, Hong Kong, Malaysia and areas of China have a high gross national product (GNP) and access to the most modern medical technologies. In these areas it is likely that trabeculectomy surgery will be utilized in the same way as in the West - as one treatment option among several. Other countries, including Loas, Cambodia, Indonesia, Vietnam or the Philippines have a GDP low on the World Bank league table. In these areas, access to any treatment may be difficult or impossible. In such areas, it may be appropriate to consider primary trabeculectomy surgery
Correspondence:

JP Diamond Bristol Eye Hospital Lower Maudlin Street Bristol BS2 2LX, UK Tel: +44 1179284653 E-mail: J.P.Diamond@ bris.ac.uk 
as the initial treatment of choice for patients with severe glaucoma.

The role of both primary trabeculectomy ${ }^{9}$ and primary cycloablation ${ }^{10}$ using the diode laser has been investigated in west Africa as the initial treatment where the alternative may be no treatment at all. Before advocating such an approach using trabeculectomy for the poorest areas of east Asia it would be vital to understand the natural history of this form of surgery. Husain has shown that this is still poorly understood and that further work is required in this area.

\section{References}

1 Leske MC, Heijl A, Hussein M, Bengtsson B, Hyman L, Komaroff E. Factors for glaucoma progression and the effect of treatment: the early manifest glaucoma trial. Arch Ophthalmol 2003; 121: 48-56.

2 Migdal C, Gregory W, Hitchings R. Long-term functional outcome after early surgery compared with laser and medicine in open-angle glaucoma. Ophthalmology 1994; 101: 1651-1656.

3 Jay JL, Allan D. The benefit of early trabeculectomy versus conventional management in primary open angle glaucoma relative to severity of disease. Eye 1989; 3: 528-535.
4 Khaw PT. Advances in glaucoma surgery: evolution of antimetabolite adjunctive therapy. J Glaucoma 2001; 10: S81-S84.

5 Raina UK, Tuli D. Trabeculectomy with releasable sutures: a prospective, randomized study. Arch Ophthalmol 1998; 116: 1288-1293.

6 Sommer A, Tielsch JM, Katz J, Quigley HA, Gottsch JD, Savitt J, et al. Relationship between intraocular pressure and primary open-angle glaucoma among white and black Americans. The Baltimore Eye Survey. Arch Ophthalmol 1991; 109: 1090-1095.

7 Leske MC, Connell AM, Schachat AP, Hyman L. The Barbados Eye Study. Prevalence of open angle glaucoma. Arch Ophthalmol 1994; 112: 821-829.

8 Bourne RR, Sukudom P, Foster PJ, Tantisevi V, Jitapunkul S, Lee PS et al. Prevelence of glaucoma in Thailand: a population based survey in Rom Klao District, Bangkok. Br J Ophthalmol 2003; 87: 1069-1074.

9 Mielke C, Dawda VK, Anand N. Intraoperative 5-fluorouracil application during primary trabeculectomy in Nigeria: a comparative study. Eye 2003; 17: 829-834.

10 Egbert PR, Fiadoyor S, Budenz DL, Dadzie P, Byrd S. Diode laser transscleral cyclophotocoagulation as a primary surgical treatment for primary open-angle glaucoma. Arch Ophthalmol 2001; 119: 424-450. 